Specialty care in the community

\title{
Improving services for patients in the community: the Rt Hon Tony Blair MP, UK Prime Minister
}

Postgrad Med J 2007;83:1.

doi: $10.1136 /$ pmi.2006.055996

The need for a more flexible workforce

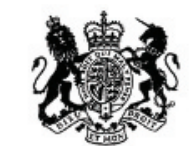

\section{DOWN IN G STREET \\ LONDON SW1A 2AA \\ www.pm.gov.uk}

THE PRIME MINISTER

13 November 2006

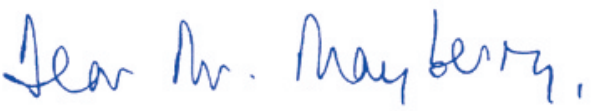

Thank you for your letter of 12 October asking me to contribute a short article in the January edition of the PMJ or make comments which could be included in an editorial on Specialty Care in the Community.

Improving services for patients in the community is high on our list of priorities. We have included a range of proposals on this in our White Paper - Our Health, Our Care, Our Say. Patients and their families want access to more local healthcare services. To deliver this we need a more flexible workforce at all levels, one that is especially skilled in building partnerships with patients.

This is a tough challenge and part of what we aim to do must be to use new and better approaches to training and developing staff, this must include both online approaches and new training packages. The issues you identify are very relevant to this.

I am sure you will know of our plans to build a more flexible medical workforce through Modernising Medical Careers. There is much scope in this important initiative for new ways of training and novel approaches that I hope PMJ would be able to contribute to.

Mr John Mayberry

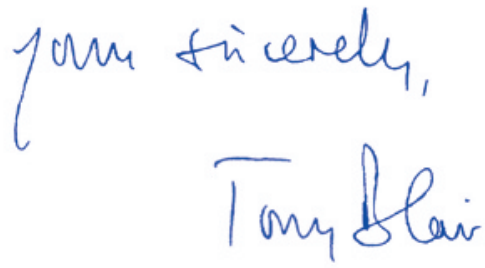

